(body), QoL, satisfaction, anxiety, depression and patient global assessment. Patient satisfaction was most commonly used $(n=10)$ as single domain with a wide variation in wording of questions and answering categories. The absolute cut-off value was the most common type of response, with large variety in value and timing of follow-up. Table 1 shows one definition for each combination of domains.

Conclusion: Our review shows that definitions for poor response to TKR are ambiguous. Our findings stress the need for an unambiguous definition of poor response to draw conclusions about the prevalence of poorresponders to TKR across hospitals and countries, and to identify patients at risk.

Abstract THU0461 -Table 1. The table shows one definition for each combination of domains

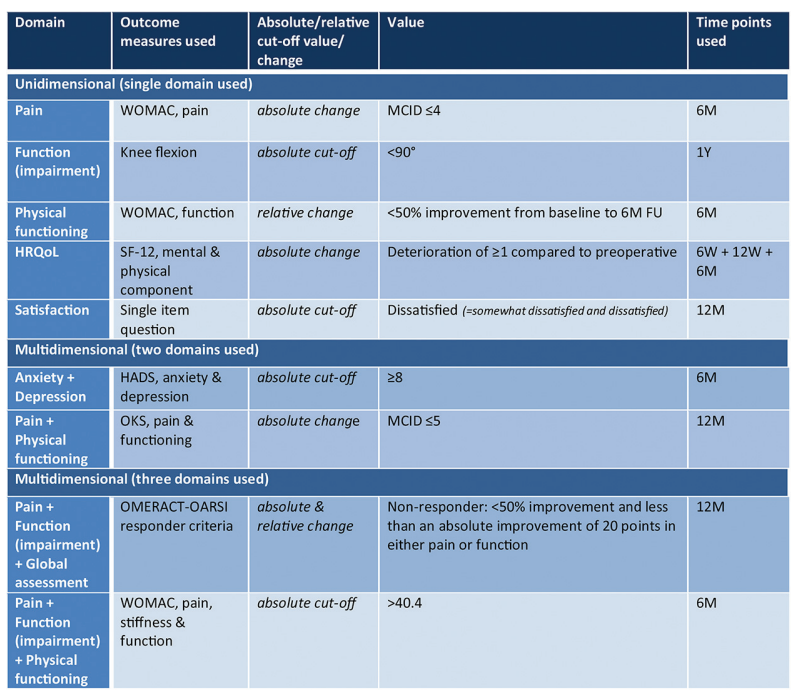

Disclosure of Interests: : None declared

DOI: 10.1136/annrheumdis-2019-eular.7983

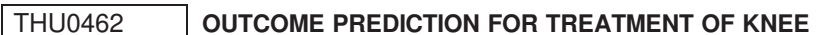 OSTEOARTHRITIS WITH A TOTAL KNEE ARTHROPLASTY. DEVELOPMENT AND VALIDATION OF A PREDICTION MODEL FOR PAIN AND FUNCTIONAL OUTCOME USING THE DUTCH ARTHROPLASTY REGISTER (LROI) DATA}

J.J. Tolk ${ }^{1}$, J.H. Waarsing ${ }^{2}$, R.P.A. Janssen ${ }^{1}$, L.N. van Steenbergen ${ }^{3}$, S.M. A. Bierma-Zeinstra ${ }^{2,4}$, Max Reijman ${ }^{4}{ }^{1}$ Máxima Medical Centre Eindhoven, Department of orthopaedic surgery and trauma, Eindhoven, Netherlands; ${ }^{2}$ Erasmus MC, University Medical Center Rotterdam, Department of general practice, Rotterdam, Netherlands; ${ }^{3}$ Dutch Arthroplasty Registry, 's Hertogenbosch, Netherlands; ${ }^{4}$ Erasmus MC, University Medical Center Rotterdam, Department of orthopaedic surgery, Rotterdam, Netherlands

Background: One of the main determinants of treatment satisfaction after total knee arthroplasty (TKA) is the fulfilment of preoperative expectations. For optimal expectation management it is useful to be able accurately predict the treatment result. Multiple patient factors that are obtained for registration in the Dutch Arthroplasty Registry (LROI) are associated with the treatment result. Therefore, these factors can potentially be utilised to estimate the most likely outcome on pain and functional outcome for an individual patient

Objectives: The aim of the present study was to create and validate models that predict residual symptoms on 10 specific outcome parameters at 12-month follow-up for patients undergoing primary TKA for knee osteoarthritis.

Methods: Data was extracted from the LROI on TKA patients who had pre- and postoperative PROMs registered in the LROI registry. Multiple logistic regression analyses were performed to construct predictive algorithms for satisfaction, treatment success, and residual symptoms concerning pain in rest and during activity, sit-to-stand movement, stair negotiation, walking, performance of activities of daily living, kneeling and squatting. Models were developed for men and women separately. We assessed predictive performance by examining measures of calibration and discrimination.

Results: Data of 7071 patients could be included for data analysis Residual complaints on kneeling ( $+72 \% / \sigma^{x} 59 \%$ ) and squatting (우이 $\sigma^{\top} 56 \%$ ) were reported most frequently, and least residual complaints were scored for walking ( $\left.+16 \% / \sigma^{x} 12 \%\right)$ and pain in rest (o $\left.18 \% / \sigma^{x} 14 \%\right)$. The predictive algorithms for residual symptoms concerning sit-to-stand movement, stair negotiation, walking, activities of daily living and treatment success showed acceptable discriminative values (AUC $0.68-0.74$ ). The prediction models for residual complaints regarding kneeling, squatting, pain and satisfaction showed the least favourable results (AUC 0.58 0.64). The calibration curves showed adequate calibration for most of the models.

Conclusion: A considerable proportion of patients has residual complaints after TKA. The present study showed that demographic and PROMs data collected for the LROI registry, can be used to predict the chance for residual symptoms after TKA. The predictive models that have been developed can be useful for individual expectation management in patients planned for TKA for knee osteoarthritis.

Acknowledgement: This study was supported by a grant from the Van Rens Foundation, and conducted with data of the Dutch Arthroplasty Registry.

Disclosure of Interests: None declared

DOI: 10.1136/annrheumdis-2019-eular.1654

\section{THU0463 EXPECTATIONS OF TREATMENT RESULT OF KNEE OSTEOARTHRITIS PATIENTS TREATED WITH A TOTAL KNEE ARTHROPLASTY. THE INFLUENCE OF DEMOGRAPHIC FACTORS, PAIN, PERSONALITY TRAITS, PHYSICAL AND PSYCHOLOGICAL STATUS}

J.J. Tolk ${ }^{1}$, R.P.A. Janssen ${ }^{1}$, T.M. Haanstra ${ }^{2}$, M. (Marieke) C. van der Steen ${ }^{2}$, S.M. A. Bierma-Zeinstra ${ }^{3,4}$, Max Reijman ${ }^{4}{ }^{1}$ Máxima Medical Center, Department of Orthopedic Surgery and Trauma, Eindhoven, Netherlands; ${ }^{2}$ Radboud University Medical Center, Department of Orthopaedic Surgery, Nijmegen, Netherlands; ${ }^{3}$ Erasmus MC, University Medical Center Rotterdam, Department of General Practice, Rotterdam, Netherlands; ${ }^{4}$ Erasmus MC, University Medical Center Rotterdam, Department of Orthopedic Surgery, Rotterdam, Netherlands

Background: Unrealistic preoperative expectations have a strong influence on the outcome after total knee arthroplasty (TKA). More insight into determinants of the level of expectations is useful in identifying patients at risk for unrealistic expectations. This information can be used in optimizing pre-operative expectation management.

Objectives: The aim of the current study was to analyze to what extent pre-operative outcome expectations of TKA patients are determined by psychological factors, demographic factors, pain, physical function and general health status.

Methods: A cross-sectional analysis of 204 patients with symptomatic and radiographic knee OA, scheduled for primary TKA was conducted. Outcome expectations were measured using the Hospital for Special Surgery knee replacement expectations survey. Independent variables included were age, sex, body mass index and patient reported outcome measures for pain, physical function, quality of life, anxiety, depression, catastrophizing, optimism and pessimism. Multiple linear regression analyses were used to evaluate associations between these variables and pre-operative outcome expectations

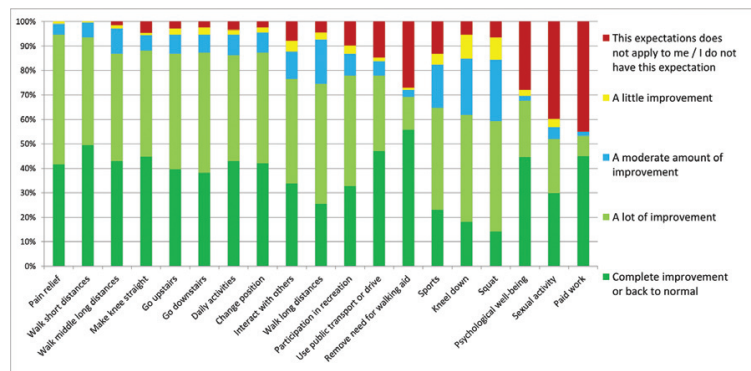

Abstract THU0463 - Figure 1

Results: The mean overall survey score on the HSS-KRES was 70.9 (SD 17.9). Distribution of expectation scores is shown in Figure 1. 